\title{
Original Article \\ Mental imagery can improve performance in a visuomotor task: a pilot study
}

\author{
, Amir-๑), Hasan Mohammadzadeh ${ }^{3}$, Mohammad Ali Nazari ${ }^{4} \oplus$ Maryam Salehi $^{1 *}$, Wesley Pyke ${ }^{2}$ \\ (1) Homayoun Javadi ${ }^{5}$ \\ 1 School of Sports and Exercise Sciences, Urmia University, Urmia, Iran; \\ 2 School of Psychology, University of Kent, Canterbury, UK; wp77@kent.ac.uk \\ 3 School of Sports and Exercise Sciences, Urmia University, Urmia, Iran; ha.moha64@gmail.com \\ 4 Department of Neuroscience, Iran University of Medical Sciences, Tehran, Iran; nazaripsycho@yahoo.com \\ 5 School of Psychology, University of Kent, Canterbury, UK; Institute of Behavioral Neuroscience, University College London, \\ London, UK; School of Rehabilitation, Tehran University of Medical Sciences, Tehran, Iran; a.h.javadi@gmail.com \\ Correspondence: ma.salehi@urmia.ac.ir
}

Citation: Salehi, M,. Pyke, P,. Mohammadzadeh, H,. AliNazari, M,. Javadi, AH. (2021). Mental imagery can improve performance in a visuomotor task: a pilot study. Humanistic approach to sport and exercise studies (HASES), 1(1), 21-29.

Received: 03 July 2021

Accepted: 28 August 2021

Published: 09 November 2021

Publisher's Note: HASES stays neutral with regard to jurisdictional claims in published maps and institutional affiliations.

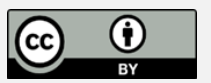

Copyright: (C) 2021 by the authors. Submitted for possible open access publication under the terms and conditions of the Creative Commons Attribution (CC BY) license.

\begin{abstract}
This experiment assessed the effectiveness of two interventions; mental imagery and physical training as compared to a control group, on their ability to improve visuomotor accuracy, measured by scores achieved on a visuomotor task. For mental imagery participants had to imagine throwing a dart and for physical training participants physically practised dart throwing. Measurements were recorded preintervention, after two weeks of training (Mid-intervention), after five weeks of training (Outcome Measure 1) and two weeks after training (Outcome Measure 2). Comparison of Mid-intervention, Outcome Measure 1 and Outcome Measure 2 with baseline showed both interventions to significantly increase performance on dart throwing compared to the Control group. Our findings show that, as well as traditional physical practise, mental imagery can effectively improve performance on a fine visuomotor task. This is an important finding highlighting possible applications of mental imagery in those with limited motor abilities to maintain or enhance motor movement.
\end{abstract}

Keywords: Imagery; Visuomotor; Athletic Performance;

\section{Introduction}

Eye-hand coordination (visuomotor coordination) is a vital element of daily life. It allows us to respond with precise movement to visual objects at an extremely fast rate. Visuomotor coordination can be as simple as grabbing an object, to more complex tasks such as batting a ball. Accuracy and ability of visuomotor coordination changes throughout the lifespan, developing throughout childhood, from infancy to adolescence (Caetano, 1995) and decreasing in older age (Lee et al., 2013). Due to many adverse events (e.g., traumatic brain injuries) or diseases (e.g., multiple sclerosis) visuomotor coordination can be drastically impaired. Although there are many physiotherapeutic treatments, there are many cases that voluntary movement is not possible; for example, in acute stroke or in sports 
neuromuscular injures. Therefore, it is extremely important to develop methods that can be utilised to improve visuomotor coordination without physical movement. One such method is mental imagery, which has previously been shown to improve performance in sport (Martin et al., 1999; Slimani et al., 2016). In this experiment, we directly compared mental imagery and physical training on their ability to improve visuomotor accuracy for dart throwing.

The use of mental imagery has been shown to improve performance in sport and procedural learning (Haghkhah, Sohrabi, Torbati, \& Hajatmand, 2014; Kornspan, Overby, \& Lerner, 2004). When used in conjunction with physical training (PT), MI has been shown to increase performance to a greater degree than PT alone (Brouziyne \& Molinaro, 2005; Vaezmousavi \& Rostami, 2009). Three types of goal-directed MI have been suggested in the literature, internal (imagining in $1^{\text {st }}$ person), external (imagining in $3^{\text {rd }}$ person) and kinaesthetic (feelings and sensations associated with movement; Cumming \& Williams, 2012). Yu et al., (2016) showed when participants used internal imagery, performance was increased for a wide range of sports, whereas when external imagery was practised, increase in performance was only seen for open sports and team games. It has also been shown that whilst external imagery may allow for particular tasks to be completed faster, internal imagery can provide greater accuracy (White \& Hardy, 1995).

In this study we aimed at comparing the effectiveness of these two methods on a single task. Using two interventions of MI and PT across 15 intervention sessions, and a Control group, the present study attempts to highlight the beneficial effects of these methods on a fine visuomotor task, in this instance, dart throwing. By investigating if these different approaches can influence performance enhancement to a similar degree, results can contribute towards the literature for clinical and practical benefits, supplying researchers and practitioners with an alternative training option. By also including a two-week retention interval, the two methods can be assessed on their ability to induce and facilitate long-term motor memory changes. It was hypothesised that in both experimental conditions (MI/PT), performance increases will be found following each respective training intervention. It is also hypothesised that each experimental condition will increase in performance compared to the Control group.

\section{Materials and Methods}

\section{2-1. Participants}

Twenty-four female participants (age range 21-26, mean $[\mathrm{SD}]=22.45[1.04]$ ) took part in this study. They were randomly assigned to one of the three experimental conditions ( $\mathrm{n}=8$ per condition; Mental Imagery/Physical Training/Control). All participants were naïve to the purpose of the study and none of them were familiar with mental imagery or dart throwing. They were right-handed and without any history of neurological disorders, with normal or corrected to normal vision. They gave written informed consent. The study was approved by the local ethics committee in the School of Sports and Exercise Sciences, Urmia University.

\section{2-2. Procedure}

Participants took part in four testing and 15 training sessions over seven weeks. See Figure 1 for the procedure. In the first session, participants were familiarised with principles of dart throwing such as holding, aiming, throwing the dart and scoring. Next, participants were asked to throw darts for three practice trials. Performance in the testing sessions was measured via 10 attempts of throwing darts and scores were recorded based on the area of the board the dart struck. Hitting the "bullseye" yielded a score of 3 . The next ring out from the centre yielded a score of 2 and finally the remainder of the board gave a score of 1 . If they missed the board, a score of zero was given. Following the preintervention testing session, participants took part in five weeks of training based on their allocated group, please see below for condition. Each week consisted of three training sessions. Two weeks into the training, participants took part in a testing session to assess their mid-intervention performance. Finally, participants took part in two more testing sessions to measure their performance immediately (Outcome Measure 1) and two weeks (Outcome Measure 2) following training. Sessions Pre- and Mid-intervention and Outcome Measure 1 followed the same procedure and took part on a separate day than the training sessions. 


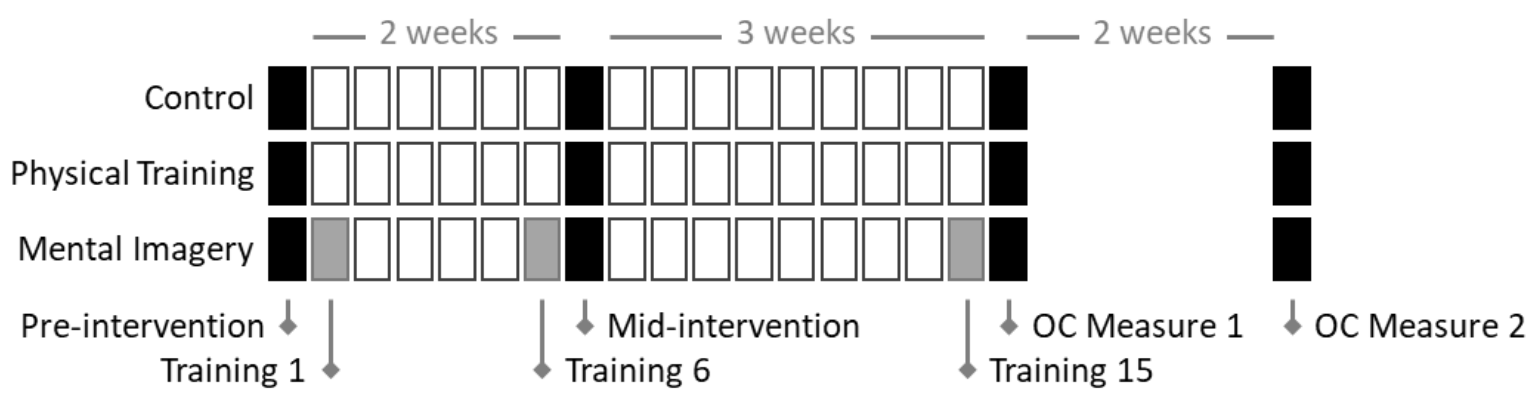

Figure 1. Procedure of the study. Training sessions were split over two and three weeks with six and nine sessions, respectively. Training sessions.

Testing sessions; 10 throws were performed and the average score is used for analysis; $\quad$ Training sessions where particpants' ability to carry out the mental imagery was assessed. OC Measure: Outcome Measure

\section{2-3. Dartboard}

In this study, a typical circular dart board compressed with paper was used with a diameter of $453 \mathrm{~mm}$ and thickness of $12 \mathrm{~mm}$. The dartboard was hung on a wall in the laboratory so that the centre of the dartboard was at a height of $1.72 \mathrm{~m}$ from the ground. A line was traced on the ground at a distance of $2.20 \mathrm{~m}$ from the dart board and the subjects would be behind the line when throwing the darts. Five metal-arrow darts weighing 25 grams and $15 \mathrm{~cm}$ long were used.

\section{2-4. Intervention Methods}

Mental Imagery (MI) - Three types of goal-directed MI have been suggested in the literature, internal (1st person), external (3rd person) and kinaesthetic (feelings and sensations associated with movement). We used an internal imagery method as previous literature suggests it to be most effective for this particular task (Hinshaw, 1991; White \& Hardy, 1995; Yu et al., 2016). Each mental imagery session lasted 30 minutes. Participants performed two blocks of 15 throwing attempts. Following each session, participants were asked to rate the quality of their imagination (Louis et al., 2008) on the scale of 1 (no mental imagery at all) to 6 (apparent mental imagery).

Physical Training (PT) - Each training session contained 15-minute of exercising in which participants performed 30 throws.

Control - Each session of the Control group consisted of 30 minutes of reading books.

2-5. Data Analysis
Average of the 10 throws in each testing session was considered for analysis of performance in dart throwing. To account for inter-subject variability, performance in the Mid-intervention, PostIntervention, Outcome Measure 1 and Outcome Measure 2 were normalised to the individual's performance in the Pre-intervention session. Due to a low number of participants and non-normal distribution of the data, Kruskal-Wallis test was used to investigate the Group effect for the three testing phases of (mid-intervention/outcome measure 1/outcome measure 2). Subsequently, Mann-Whitney U test was used to compare the normalised-performance of the participants in the different group of training (Mental Imagery/Physical Training) with the Control group. Cliff's Delta effect size is reported.

Additionally, to investigate the effect of the MI intervention on performance, a Friedman nonparametric tests on MI self-reported ratings was run. Subsequently a Wilcoxon Signed Ranks test was run to compare values in different training sessions. Finally, to investigate the relation between these scores and performance, a Spearman's rankorder correlation was run between the scores in Training 15 and normalised performance in Outcome Measure 2.

\section{Results}

All participants followed the procedure of the study and took part in all of the sessions. Table 1 shows the summary of the performance of the participants in different groups and different testing sessions.

Table 1. Summary of the mean (SD) value of performance of participants in different groups. 
Humanistic approach to sport and exercise studies (HASES); 2021, 1(1), 24 of 29

\begin{tabular}{lllll}
\hline Mental Imagery & $18.70(5.45)$ & $22.02(6.69)$ & $25.52(8.10)$ & $25.30(4.24)$ \\
Physical Training & $18.20(4.98)$ & $18.98(5.23)$ & $24.02(5.24)$ & $22.35(4.90)$ \\
Control & $19.48(1.34)$ & $17.15(3.32)$ & $19.18(5.12)$ & $16.73(5.57)$ \\
\hline
\end{tabular}

Normalised data was calculated for each participant, see Figure 2. Multi-variate KruskalWallis over the three testing sessions and groups showed significant effect for only the Outcome Measure 2. See Table 2 for the summary of these

Table 3 shows the summary of the Mann-Whitney $\mathrm{U}$ tests conducted on the data. Results show that tests. Subsequently we ran Mann-Whitney U tests on the Outcome Measure 2 values to investigate difference between the training groups with the Control group.

participants in all the training groups performed better in the Outcome Measure 2 compared to the Control condition.

Table 2. Summary of the Kruskal-Wallis tests ran on the normalised performance values.

\begin{tabular}{llllll}
\hline & & & \multicolumn{3}{c}{ Mean Rank } \\
\cline { 5 - 6 } Test & $\boldsymbol{\chi}^{\mathbf{2}}(\mathbf{2})$ & $\boldsymbol{p}$ & MI & PT & Control \\
\hline Mid-Intervention & 4.163 & 0.125 & 15.00 & 14.13 & 8.38 \\
Outcome Measure 1 & 1.970 & 0.374 & 13.44 & 14.38 & 9.69 \\
Outcome Measure 2 & 7.505 & $0.023^{*}$ & 16.13 & 14.38 & 7.00 \\
\hline
\end{tabular}

Note: MI: Mental Imagery; PT: Physical Training; ${ }^{*} p<0.05$

To investigate how well the participants were able to carry out the interventions, i.e. perceived mental imagery rating, we ran a Friedman non-parametric test on scores recorded in three of the training sessions (Training 1/Training 6/Training 15). This test showed a significant effect $(\chi 2(2)=9.333, \mathrm{p}=$ 0.009; Mean Rank Training 1: 1.38, Training 6: 2.13, and Training 15: 2.50; mean[SD] Training 1: 4.37[0.69], Training 2: 5.00[0.01], Training 3:
5.25[0.43]). This shows that participants achieved a better mental imagery rating in later sessions. Spearman's rank-order correlation between Mental Imagery ratings in Training 15 and normalised performance in Outcome Measure 1, which is the following day after Training 15 (see Figure 1), and Outcome Measure 2, which showed significant difference between groups (see Table 2), showed no-significant correlation for either of the parameters (p's > 0.192).

Table 3. Summary of the Mann-Whitney U test; comparing the normalised performance of the participants in the training groups with the Control group

\begin{tabular}{llll}
\hline & \multicolumn{3}{l}{ Outcome Measure 2 } \\
\cline { 2 - 4 } Comparison & $\mathrm{U}$ & $\boldsymbol{p}$ & Delta \\
\hline Mental Imagery vs. Control & 9.00 & $0.016^{*}$ & 0.718 \\
Physical Training vs. Control & 11.00 & $0.027^{*}$ & 0.656 \\
\hline
\end{tabular}

Notes: normalised performance is calculated based on performance in each group divide by the performance in the pretraining phase. Cliff's Delta values are reported for effect size. $* \mathrm{P}<0.05$ 
Humanistic approach to sport and exercise studies (HASES); 2021, 1(1), 25 of 29

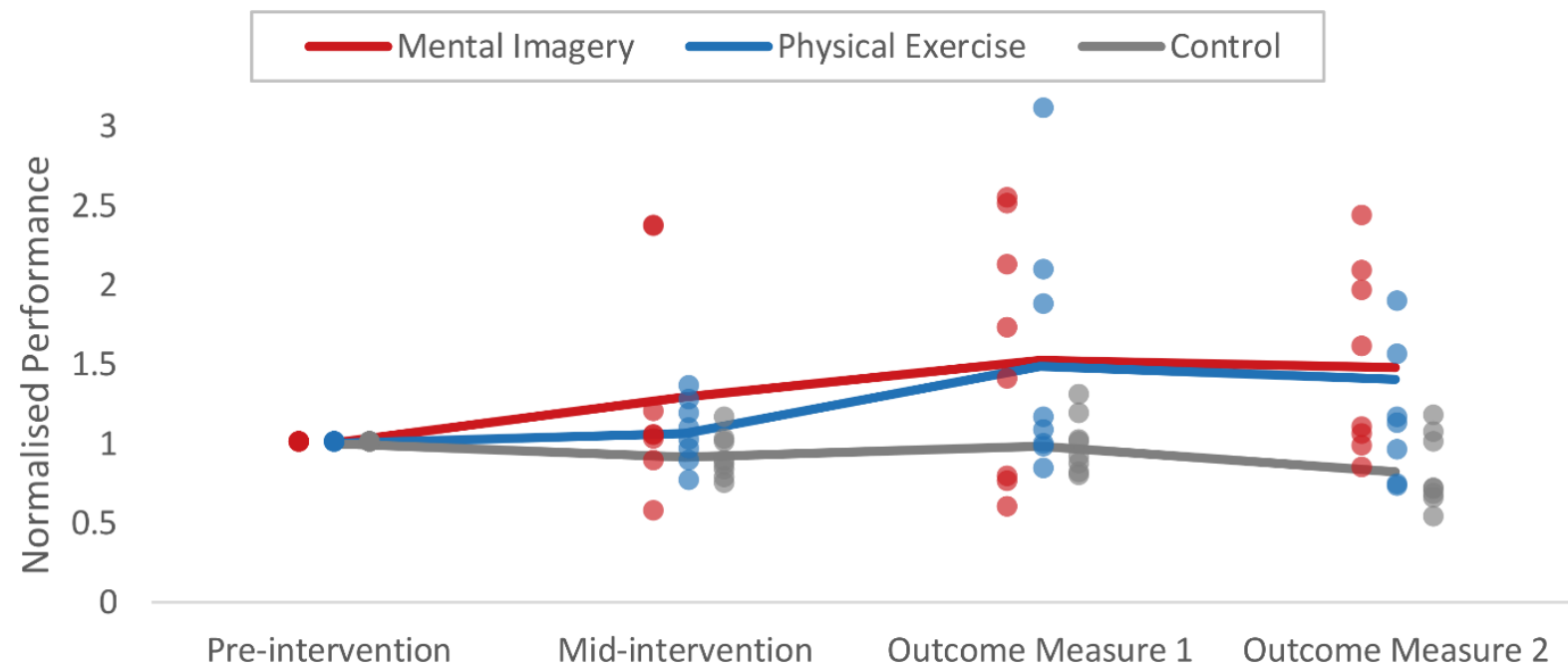

Figure 2. Normalised performance of the participants. Dots indicate individual normalised performance in each experimental group. Dots represent individual datapoints for each participant in each condition and session. Lines indicate the mean of the values in each group and session

\section{Discussion}

As hypothesised, the results above suggest that both conditions (Mental Imagery and Physical Training) increased performance from Pre-intervention in both Outcome Measure 1 and significantly so in Outcome Measure 2 compared to the Control group. For Mental Imagery, analysis of scores recorded during three of the training sessions (Training 1/Training 6/Training 15) showed an increase, from Training 1 to Training 15. This increase in scores, however, was not correlated with superior performance in the Outcome Measure 2.

When looking at the increase in performance across both interventions, it is important to consider the mechanisms influenced by each in order to understand the results. It is likely that both improved performance on dart throwing through the process of reconsolidation. By either physically practising the task, or imagining it, with the desired consequence in mind, the brain is repeatedly exposed to similar mechanisms (Newell, 1991), thus, improving motor skills. Neuroimaging studies indicate that the primary motor cortex (M1) is engaged during both MI and PT of motor tasks (Karni et al., 1995) with M1 also shown to be a vital element in the consolidation process of newly learned motor skills (Muellbacher et al., 2002; Ziemann, 2004). From M1, the acquired skill follows a pathway where it will eventually reach the cerebellum (Imamizu et al., 2003). Following successful completion of a motor action, over time, long-term potentiation (LTP) occurs in both M1 and the cerebellum (Krakauer \& Shadmehr, 2006;
Ma et al., 2010; Packard \& Knowlton, 2002). Failed attempted actions, however, encourage long-term depression (LTD), thus fine-tuning mechanisms which in time allows for greater accuracy and ease of execution (Hirano, 2013).

Interestingly, the results obtained from the current study contradict previous meta-analysis findings, in that the MI condition increased performance to the same degree as the PT condition compared to the control group. Although Feltz, Landers and Becker (1988) found MI to yield twice as great results on motor and accuracy tasks compared to control groups, they found physical practise to be $41-45 \%$ more effective than MI when compared alone. However, this meta-analysis failed to include differences between internal $\left(1^{\text {st }}\right.$ person) and external ( $3^{\text {rd }}$ person), something that Hinshaw (1991) showed in their meta-analysis to be vital for explaining performance increases due to MI. In the present study, as internal imagery was used, this may in part explain why in this instance MI displayed similar results to PT, compared to a control group. Similarly, previous experiments focussing on MI in sport, have included an additional session whereby $\mathrm{MI}$ and PT were combined (Kohl, Ellis, \& Roenker, 1992; McBride \& Rothstein, 1979; White, Ashton, \& Lewis, 1979). Almost always, the combination of MI with PT yielded greater performance increases than either of the two conditions alone. This suggest that MI is most effectively used as an accompaniment to PT. Although an extra condition was included, each of 
the studies still found an improvement for MI alone compared to the control group.

Whilst similar performance increases for visuomotor coordination were found in both experimental conditions, each condition has strengths and weaknesses for practical implementation. For example, if one wanted to increase skill in a sport, it would be appropriate to use either method. In a clinical setting, however, some of the methods may not be accessible to the entire population. By highlighting that both are as effective as one another, the appropriate method can be chosen to suit the need of the individual.

Those suffering a brain lesion (region dependent, for example, visual object agnosia, see Behrmann, Winocur, \& Moscovitch, 1992) may be able to partake in MI for rehabilitation, but not PT. In patients suffering from a stroke affecting motor deficits, when used alongside traditional rehabilitation methods, MI was shown to aid motor rehabilitation significantly more than those methods alone (Page et al., 2001). Moreover, MI can be used in most instances for rehabilitation of motor skills (Jackson et al., 2001) including physical injuries in sport (Green, 1992), unless damage is present in certain areas (e.g. in the parietal lobes; Sirigu et al., 1996).

With these potential applications in mind, it is important to take in to account the sample size of this pilot study. Whilst a significant result was obtained, as well as a relatively large effect size, cautious interpretation is encouraged. This study should be used as an example of how mental imagery can be an effective method of improving performance on a fine visuomotor task, thus a precursor to a more robust study including an increased and wider sample population.

\section{Conclusions}

This study has highlighted the usefulness of mental imagery and physical training in their ability to enhance visuomotor coordination based on scores achieved on a dart throwing task. Whilst we have shown the effectiveness of both protocols in a small sample of healthy students, future research should include a greater sample population, as well as patient and elite samples, to assess the effectiveness of individual methods in more specific populations. With other recent promising research, as well as the results achieved in this study, the effects of these non-pharmacological methods of cognitive enhancement can stretch into multiple domains.

Author Contributions: The authors participated in Conception of the work, Acquisition of data, Analysis and interpretation of data for the work, Writing, and revising the work, Final approval of the version to be published and agreement to be accountable for all aspects of the work.

Data Availability Statement: The measured data used to support the findings of this study are available from the corresponding author upon request.

Conflicts of Interest: Authors indicate no conflict of interest.

\section{References}

Behrmann, M., Winocur, G., \& Moscovitch, M. (1992). Dissociation between mental imagery and object recognition in a brain-damaged patient. $\quad$ Nature, 359, 636. https://doi.org/10.1038/359636a0. [Google Scholar]

Brouziyne, M., \& Molinaro, C. (2005). Mental imagery combined with physical practice of approach shots for golf beginners. Perceptual and Motor Skills, 101(1), 203-211. https://doi.org/10.2466/pms.101.1.203-211.

[Google Scholar]

Caetano, C. (1995). Development of Visuomotor Coordination in School-Age Children: The Bimanual Coordination Test. Developmental Neuropsychology, 11(2), 181-199. https://doi.org/10.1080/87565649509540612.

[Google Scholar]

Cumming, J., \& Williams, S. E. (2012). The Role of Imagery in Performance. In S. Murphy (Ed.), Handbook of Sport and Performance Psychology. Oxford University Press. [Google Scholar]

Feltz, D. L., Landers, D. M., \& Becker, B. J. (1988). Enhancing Human Performance. A Revised Meta-Analysis of the Mental Practice Literature on Motor Skill Learning. https://doi.org/10.17226/786. [Google Scholar]

Green, L. B. (1992). The Use of Imagery in the Rehabilitation of Injured Athletes. The Sport Psychologist, 6(4), 416-428. [Google Scholar]

Grouios, G. (1992). Mental Practice: A Review. Journal of Sport Behavior, 15(1), 1-14. [Google $\underline{\text { Scholar }]}$ 
Haghkhah, A., Sohrabi, M., Torbati, H. T., \& Hajatmand, H. (2014). The Effect of Mental Imagery Focus of Attention on Performance and Learning of Children Dart Throwing Skill The Effect of Mental Imagery Focus of Attention on Performance and Learning of Children Dart Throwing Skill. January. [Google Scholar]

Hinshaw, K. E. (1991). The Effects of Mental Practice on Motor Skill Performance: Critical Evaluation and Meta-Analysis. Imagination, Cognition and Personality. https://doi.org/10.2190/x9ba-kj68-07an-qmj8. [Google Scholar]

Hirano, T. (2013). Long-term depression and other synaptic plasticity in the cerebellum. Proceedings of the Japan Academy, Series B, 89(5), 183-195. https://doi.org/10.2183/pjab.89.183. [Google Scholar]

Imamizu, H., Kuroda, T., Miyauchi, S., Yoshioka, T., \& Kawato, M. (2003). Modular organization of internal models of tools in the human cerebellum. Proceedings of the National Academy of Sciences, 100(9), 5461-5466. [Google Scholar]

Jackson, P. L., Lafleur, M. F., Malouin, F., Richards, C., \& Doyon, J. (2001). Potential role of mental practice using motor imagery in neurologic rehabilitation. Archives of Physical Medicine and Rehabilitation, 82(8), 1133-1141. [Google Scholar]

Karni, A., Meyer, G., Jezzard, P., Adams, M. M., Turner, R., \& Ungerleider, L. G. (1995). Functional MRI evidence for adult motor cortex plasticity during motor skill learning. Nature, 377(6545), 155-158. [Google Scholar]

Kohl, R. M., Ellis, S. D., \& Roenker, D. L. (1992). Alternating actual and imagery practice: preliminary theoretical considerations. Research Quarterly for Exercise and Sport, 63(2), 162170.

https://doi.org/10.1080/02701367.1992.1060757 6 [Google Scholar]

Kornspan, A. S., Overby, L. Y., \& Lerner, B. S. (2004). Analysis and Performance of Preperformance Imagery and Other Strategies on a Golf Putting Task. Journal of Mental Imagery, 28(3), 59-74. https://doi.org/10.1029/2009JC005369. [Google Scholar]
Kosslyn, S. M., DiGirolamo, G. J., Thompson, W. L., \& Alpert, N. M. (1998). Mental rotation of objects versus hands: Neural mechanisms revealed by positron emission tomography. Psychophysiology, 35(2), 151-161. https://doi.org/10.1017/S0048577298001516. [Google Scholar]

Kosslyn, S. M., Ganis, G., \& Thompson, W. L. (2001). Neural foundations of imagery. In Nature Reviews Neuroscience (Vol. 2, Issue 9, pp. 635-642). https://doi.org/10.1038/35090055. [Google Scholar]

Krakauer, J. W., \& Shadmehr, R. (2006). Consolidation of motor memory. Trends in Neurosciences, 29(1), 58-64. https://doi.org/10.1016/j.tins.2005.10.003. [Google Scholar]

Lee, N. K., Kwon, Y. H., Son, S. M., Nam, S. H., \& Kim, J. S. (2013). The Effects of Aging on Visuomotor Coordination and Proprioceptive Function in the Upper Limb. Journal of Physical Therapy Science, 25(5), 627-629. https://doi.org/10.1589/jpts.25.627. [Google Scholar]

Louis, M., Guillot, A., Maton, S., Doyon, J., \& Collet, C. (2008). Effect of imagined movement speed on subsequent motor performance. Journal of Motor Behavior, 40(2), 117-132. [Google Scholar]

Ma, L., Wang, B., Narayana, S., Hazeltine, E., Chen, X., Robin, D. A., Fox, P. T., \& Xiong, J. (2010). Changes in regional activity are accompanied with changes in inter-regional connectivity during 4 weeks motor learning. Brain Research, 1318, 64-76. https://doi.org/10.1016/j.brainres.2009.12.073. [Google Scholar]

Martin, K. A., Moritz, S. E., \& Hall, C. R. (1999). Imagery use in sport: A literature review and applied model. In Sport Psychologist (Vol. 13, Issue 3, pp. 245-268). Human Kinetics Publishers Inc. https://doi.org/10.1123/tsp.13.3.245. [ [ [Google Scholar]

McBride, E. R., \& Rothstein, A. L. (1979). Mental and Physical Practice and the Learning and Retention of Open and Closed Skills. Perceptual and Motor Skills, 49(2), 359-365. https://doi.org/10.2466/pms.1979.49.2.359. [Google Scholar] 
Humanistic approach to sport and exercise studies (HASES); 2021, 1(1), 26 of 29

Morris, T., Spittle, M., \& Watt, A. (2005). Imagery

In Sport. Human Kinetics. [Google Scholar]. 
Muellbacher, W., Ziemann, U., Wissel, J., Dang, N., Kofler, M., Facchini, S., \& Hallett, M. (2002). Early consolidation in human primary motor cortex. Nature, 415(6872), 640-644. [Google Scholar]

Newell, K. M. (1991). Motor skill acquisition. Physical Therapy, 71(2), 123-139. https://doi.org/10.1146/annurev.ps.42.020191.0 01241. [Google Scholar]

Packard, M. G., \& Knowlton, B. J. (2002). Learning and Memory Functions of the Basal Ganglia. Annual Review of Neuroscience, 25(1), 563-593.

https://doi.org/10.1146/annurev.neuro.25.11270 1.142937. [Google Scholar]

Page, S. J., Levine, P., Sisto, S., \& Johnston, M. V. (2001). A randomized efficacy and feasibility study of imagery in acute stroke. Clinical Rehabilitation, 15(3), 233-240. [Google Scholar]

Pearson, J. (2019). The human imagination: the cognitive neuroscience of visual mental imagery. Nature Reviews Neuroscience. https://doi.org/10.1038/s41583-019-0202-9. [Google Scholar]

Pearson, J., Naselaris, T., Holmes, E. A., \& Kosslyn, S. M. (2015). Mental Imagery: Functional Mechanisms and Clinical Applications. Trends in Cognitive Sciences, 19(10), 590-602. https://doi.org/10.1016/j.tics.2015.08.003. [Google Scholar]

Richter, W., Somorjai, R., Summers, R., Jarmasz, M., Menon, R. S., Gati, J. S., Georgopoulos, A. P., Tegeler, C., Ugurbil, K., \& Kim, S. G. (2000). Motor area activity during mental rotation studied by time-resolved single-trial fMRI. Journal of Cognitive Neuroscience, 12(2), 310-320. http://www.ncbi.nlm.nih.gov/pubmed/10771414 . [Google Scholar]

Sirigu, A., Duhamel, J.-R., Cohen, L., Pillon, B., Dubois, B., \& Agid, Y. (1996). Sirigu, A., Duhamel, J.-R., Cohen, L., Pillon, B., Dubois, B., \& Agid, Y. (1996). The Mental Representation of Hand Movements After Parietal Cortex Damage. Science, 273(5281), 1564-1568. Science, 273(5281), 1564-1568. [Google Scholar]

Slimani, M., Tod, D., Chaabene, H., Miarka, B., \& Chamari, K. (2016). Effects of mental imagery on muscular strength in healthy and patient participants: A systematic review. In Journal of Sports Science and Medicine (Vol. 15, Issue 3, pp. 434-450). Journal of Sport Science and Medicine. http://www.jssm.org. [Google $\underline{\text { Scholar] }}$

Vaezmousavi, S. M., \& Rostami, R. (2009). The Effects of Cognitive and Motivational Imagery on Acquisition, Retention and Transfer of the Basketball Free Throw. World Journal of Sport Sciences, 2(2), 129-135. [Google Scholar]

White, A., \& Hardy, L. (1995). Use of different imagery perspectives on the learning and performance of different motor skills. British Journal of Psychology, 86, 169-180. https://doi.org/10.1111/j.20448295.1995.tb02554.x. [Google Scholar]

White, K., Ashton, R., \& Lewis, S. (1979). Learning a complex skill: Effects of mental practice, physical practice, and imagery ability. International Journal of Sport Psychology, 10(2), 71-78.. [Google Scholar].

Yu, Q. H., Fu, A. S. N., Kho, A., Li, J., Sun, X. H., \& Chan, C. C. H. (2016). Imagery perspective among young athletes: Differentiation between external and internal visual imagery. Journal of Sport and Health Science, 5(2), 211-218. https://doi.org/10.1016/j.jshs.2014.12.008. [Google Scholar]

Ziemann, U. (2004). Learning Modifies Subsequent Induction of Long-Term Potentiation-Like and Long-Term Depression-Like Plasticity in Human Motor Cortex. Journal of Neuroscience, 24(7), 1666-1672. https://doi.org/10.1523/JNEUROSCI.501603.2004. [Google Scholar] 


\title{
فصلنامه رويكرد انسانى در مطالعات ورزشى
}

$\underline{\mathrm{HA}}>\mathrm{E} \mathrm{S}$

http://hasesjournal.com/

\section{تصوير سازى ذهنى مى تواند عملكر د را در تكليف ديدارى حر كتى بهبود بخشد: يك مطالعه آزمايشى}

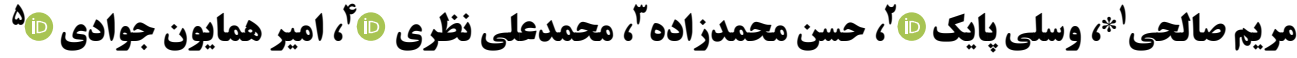

\author{
' دانشكده علوم ورزشى، دانشخاه اروميه، اروميه، ايران. \\ ' ' دانشكده روانشناسى، دانشعاه كنت، كانتربرى، انغلستان. \\ " مانشكده علوم ورزشى، دانشكاه اروميه، اروميه، ايران. \\ " كرووه علوم اعصاب، دانشكاه علوم بز شكى ايران، تهران، ايران.
}

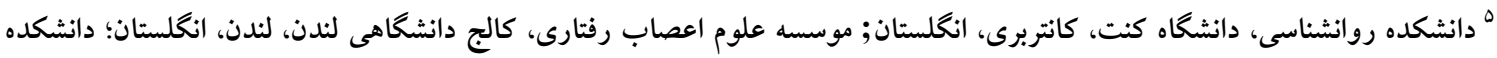

توانبشى، دانشحاه علوم يزشكى تهران، تهران، ايران.

" نويسنده مسئول: ma.salehi@urmia.ac.ir

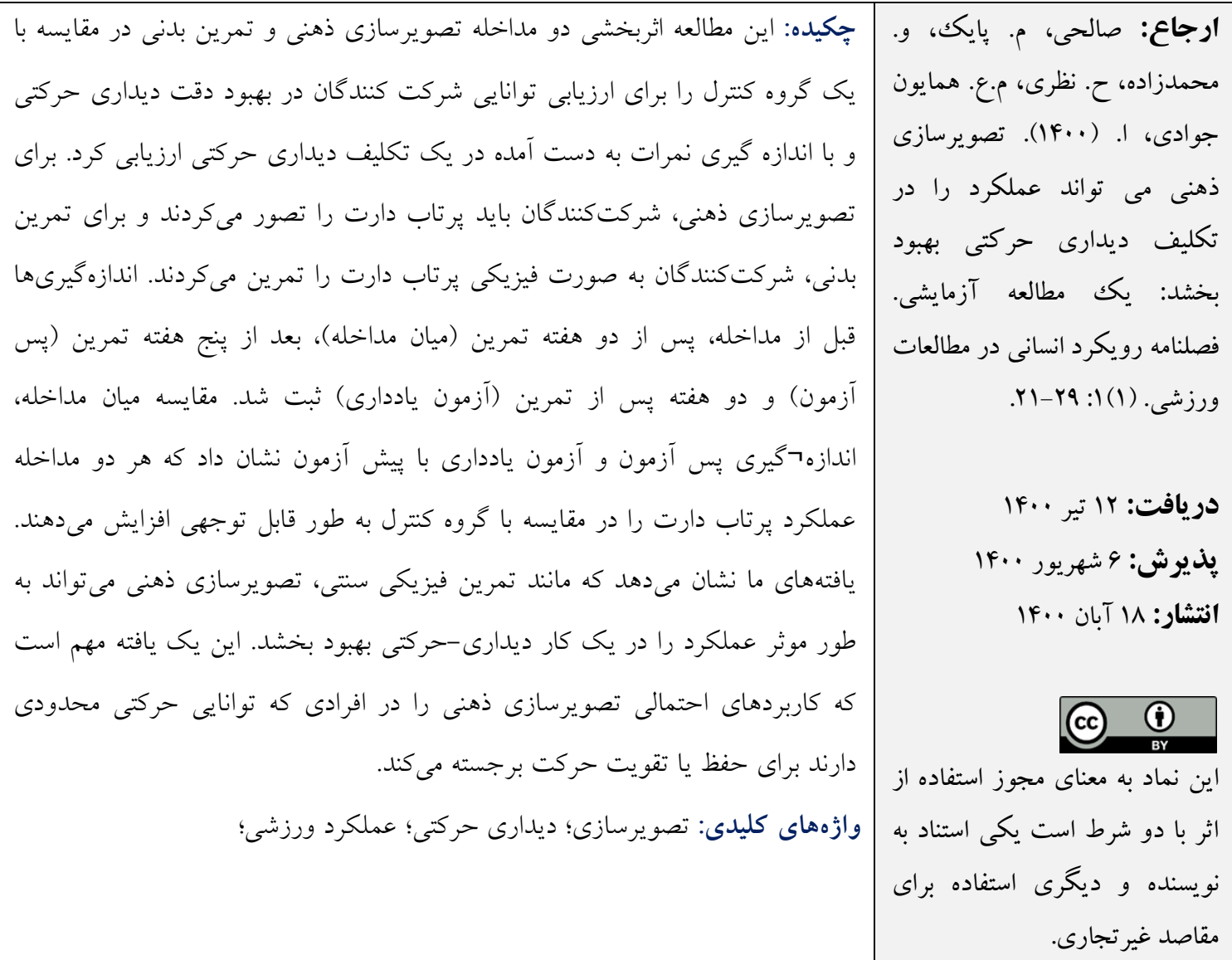

